\title{
O ensino de Sciencias Naturaes e os alunos surdos do século XIX
}

\section{The teaching of Natural Sciences and deaf students in the nineteenth century}

\author{
Cássia Geciauskas Sofiato ${ }^{1}$ \\ http://orcid.org/0000-0001-52919658 \\ Ronaldo Santos Santana ${ }^{1}$ \\ http://orcid.org/0000-0002-38133541
}

\begin{abstract}
Resumo: A educação formal de alunos surdos no Brasil teve início no século XIX, mais precisamente em 1856, por meio da fundação da primeira instituição especializada denominada Collegio Nacional para Surdos-Mudos de ambos os gêneros, na cidade do Rio de Janeiro. Este artigo objetiva apresentar indícios de como era desenvolvido o ensino de Ciências para alunos surdos no período de 1856 a 1889, no Collegio Nacional para Surdos-Mudos de Ambos os Sexos. A pesquisa em questão é de abordagem qualitativa e do tipo documental. O corpus documental foi constituído por fontes primárias, tais como coleções de relatórios e leis específicas do Império do Brasil. Por meio do estudo realizado percebe-se que o ensino de sciencias naturaes não estava previsto no currículo prescrito para os alunos surdos em seus anos de escolaridade no Instituto, mas que perpassava o referido currículo por meio de atividades extraclasse e desenvolvidas no museu escolar.
\end{abstract}

Palavras-chave: Educação dos surdos. Ensino de ciências. Educação especial.

\begin{abstract}
The formal education of deaf students in Brazil began in the nineteenth century, more precisely in 1856, with the foundation of the first specialized institution in this regard, the National College for the Deaf-Mutes of Both Genders, in the city of Rio de Janeiro. The present study aims to present evidence of the development of science education for deaf students from 1856 to 1889 at the National College for the Deaf-Mutes of Both Sexes. This research is qualitative and documentary. The documentary corpus consisted of primary sources, such as a compilation of reports and specific Laws of the Brazilian Empire. With this study, we note that the teaching of natural sciences was not expected in the curriculum prescribed for deaf students in their school years within the institute, but that it was integrated into the said curriculum through extra-class activities developed in the school museum.
\end{abstract}

Keywords: Death education. Science teaching. Special education.

\footnotetext{
${ }^{1}$ Universidade de São Paulo (USP), Faculdade de Educação (FE), São Paulo, SP, Brasil.

E-mail: cassiasofiato@usp.br
} 
Sofiato, C. G.; Santana, R. S.

\section{Introdução}

Antes do século XIX não encontramos registros documentais que comprovem iniciativas de educação para pessoas que nasciam surdas no Brasil. Ademais, registra-se aqui a dificuldade de encontrar fontes primárias relativas ao período, o que coloca ao pesquisador um grande desafio: entender melhor e ressignificar o passado e empreender outras leituras sobre os fatos. Em que pese a constatação feita anteriormente, faz-se mister destacar que estudos do século XIX ainda são fundamentais para que possamos conhecer os alicerces da educação de surdos e seu impacto nos séculos subsequentes, levando em consideração os desafios hodiernos da educação desses alunos, no que tange ao ensino de línguas e dos conteúdos de diferentes áreas do conhecimento, pauta constante em discussões da área.

A primeira instituição educacional para surdos de caráter oficial, ou seja, assumida pelo governo Imperial, data de 1856 e foi fundada com o nome de do Collegio Nacional para Surdos-Mudos de Ambos os Sexos.

Figura 1 - Anúncio do Collegio Nacional para Surdos-Mudos de ambos os Sexos

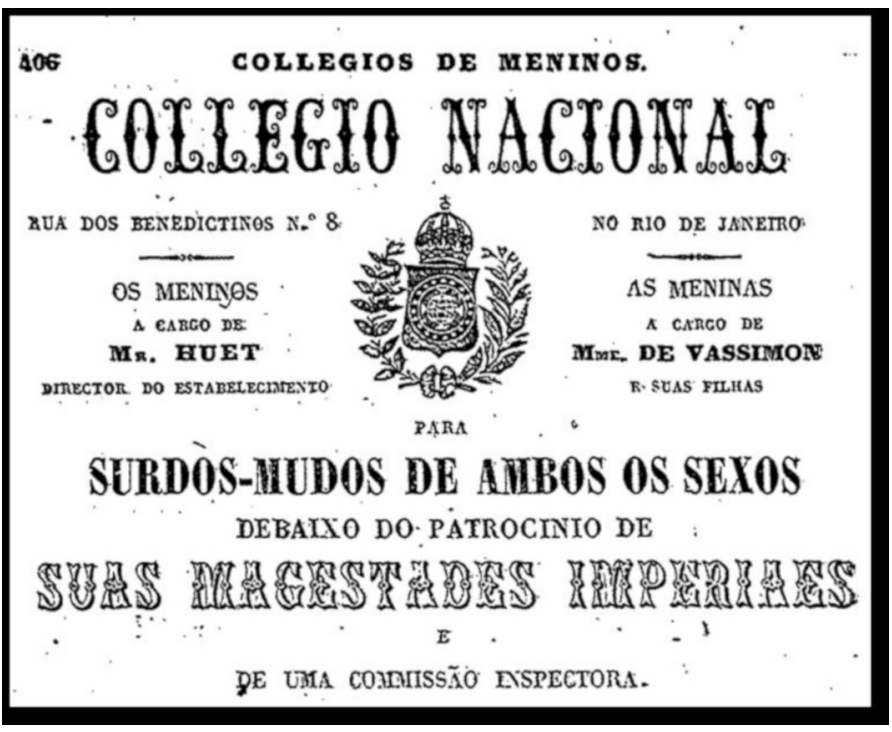

Parte de uma página do Almanak Laemmert que se refere especificamente ao Collegio Nacional para SurdosMudos de Ambos os Sexos.

Fonte: Laemmert (1856, p. 406) ${ }^{2}$.

${ }^{2} \mathrm{O}$ Almanak Laemmert foi publicado até o ano de 1889. 
O Almanak Laemmert: anuário administrativo, agricola, mercantil, profissional e industrial, vigente de 1844 a 1899, de autoria de Henrique e Eduardo Laemmert, “[...] realizava uma radiografia dos espaços públicos e privados da Corte e Província do Rio de Janeiro a partir dos seus anúncios" (LIMEIRA; SOUZA, 2008, p. 329). Detalhava,

[...] em mais de mil páginas de cada edição, profissionais dos mais diversos ramos de atividade (advogados, professores, tradutores, corretores), periódicos publicados na Corte, instituições religiosas, sociedades de leitura, comércio, livrarias e tipografias, academias (de medicina, de artes), escolas e colégios (públicos, privados, militares, religiosos), hospitais e hospícios, asilos e associações, museus, seminários, secretarias, conventos, teatros, aulas avulsas, bibliotecas, funcionários do Paço Imperial e das câmaras municipais, bispos e arcebispos do Brasil, diretores das escolas da província, lojas de aluguel de escravos, por exemplo. (LIMEIRA; SOUZA, 2008, p. 328-329).

A instituição foi criada na província do Rio de Janeiro, por D. Pedro II, a pedido do professor surdo francês E. Huet, e tinha a seguinte pretensão: "Este estabelecimento, fundado por M. E. Huet, ex-diretor da Instituição dos Surdos-Mudos de Bourges, e destinado à regeneração intellectual e moral dos Surdos-Mudos do Brasil, admitte qualquer individuo dos dous sexos, desde a idade de 7 a 16 annos" (LAEMMERT, 1856, p. 406).

Assim como os demais estabelecimentos educacionais do Império, o Collegio Nacional para Surdos-Mudos de Ambos os Sexos tinha um programa educacional destinado a alunos de sete a dezesseis anos e compreendia um curso de seis anos, cujo diferencial era o público-alvo que atendia, constituído por alunos surdos. O referido curso, com base na abordagem educacional oralista, que "[...] visa capacitar a pessoa surda a utilizar a língua da comunidade ouvinte na modalidade oral como única possibilidade linguística" (SÁ, 1999, p. 69), consistia no oferecimento de lições de pronúncia de articulação e de leitura dos lábios, além das disciplinas constantes na figura 2, no ano de sua fundação.

Figura 2 - Disciplinas oferecidas no Collegio Nacional para Surdos-Mudos de Ambos os Sexos

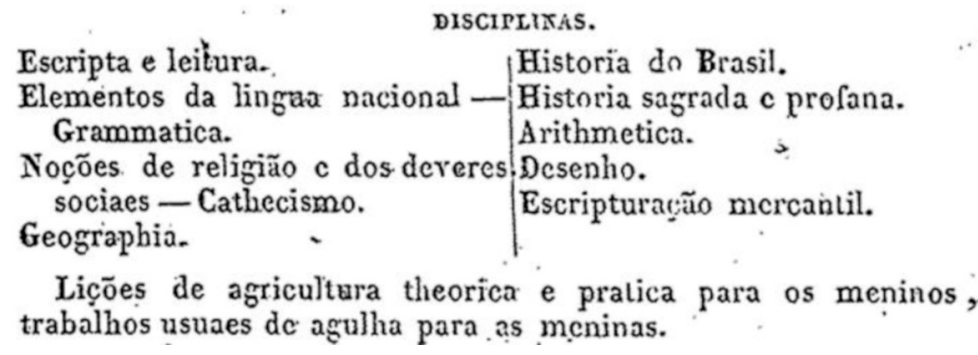

Fonte: Laemmert (1856, p. 406). 
O nome do estabelecimento foi alterado para Imperial Instituto para Surdos-Mudos de ambos os sexos um ano depois ${ }^{3}$. Ao observarmos o primeiro currículo delineado para o trabalho com os alunos surdos, percebemos que a disciplina de sciencias naturaes ${ }^{4}$ ou outra que abarcasse princípios das ciências physicas não estava incluída. Sabe-se que no contexto da educação do Império, desde o ano de 1854, o Decreto n. ${ }^{\circ}$ 1331-A, que aprovou a Reforma do Ensino Primário e Secundário, permitia que nos currículos das escolas primárias constasse “[...] os principios das sciencias physicas e da historia natural applicaveis aos usos da vida" (BRASIL, 1854, p. 45, grifo nosso). Tal decreto ficou conhecido como Reforma Couto Ferraz.

Esse fato nos chamou a atenção e nos levou aos seguintes questionamentos: por que sciencias naturaes não aparecia no currículo para alunos surdos se em outros colégios, no mesmo período, a disciplina estava presente nas matrizes curriculares? Como exemplo, citamos o Imperial Instituto de Meninos Cegos, instituição fundada três anos antes que a dos surdos e incluía a disciplina em questão em seu currículo. E os questionamentos seguiam: conteúdos relativos a essa disciplina eram trabalhados com alunos surdos? Quais atividades eram desenvolvidas na escola com tais alunos que se relacionavam ao ensino de Ciências? Os referidos questionamentos ganharam mais potência com a afirmação de Couto Ferraz, Ministro e Secretário dos Negócios do Império, que, em seu relatório do ano de 1856, expressou que o Collegio Nacional para Surdos-Mudos de Ambos os Sexos era uma escola de ensino elementar e secundário.

Segundo o seu programa, o instituto recebe alumnos de um e de outro sexo, mediante uma pensão annual; alimenta-os, dá-lhes casa para morada, ensina-lhes tudo quanto concerne á instrucção primaria e secundaria, á religião e á moral, e dá-lhes noções de artes e sciencias (BRASIL, 1856, p. 70, grifo nosso).

Dessa forma, o objetivo deste estudo é apresentar indícios de como era desenvolvido o ensino de Ciências para alunos surdos, no período de 1856 a 1889, no Imperial Instituto dos Surdos-Mudos, com base no currículo e nos registros de atividades declaradas pelos diretores em seus relatórios anuais. Tal recorte temporal foi estabelecido em função da importância que o Segundo Reinado teve para a educação de surdos no Brasil e, também, em virtude da escassez de pesquisas dessa natureza. O estudo se assentou nessa instituição por ter sido a primeira criada no Brasil com o intuito de oferecer a educação para alunos surdos no século XIX e por ocupar um papel de destaque até o presente momento.

O presente estudo é de abordagem qualitativa e se caracteriza como documental. De acordo com Gil (2002, p. 45), “[...] a pesquisa documental vale-se de materiais que não recebem ainda um tratamento analítico, ou que ainda podem ser reelaborados de acordo com os objetos da pesquisa". Como fontes documentais foram utilizados relatórios dos diretores do Imperial Instituto dos Surdos-Mudos e relatórios dos Ministros e Secretários dos Negócios do Império, no recorte temporal explicitado.

\footnotetext{
${ }^{3}$ Utilizaremos a expressão Imperial Instituto dos Surdos-Mudos, por ser a forma mais usada na literatura da área.

${ }^{4}$ Neste estudo, em alguns momentos, utilizaremos o termo sciencias natuares e sciencias, levando em consideração a forma original de sua grafia no século XIX.
} 


\section{Ensino de Ciências no século XIX}

Antes de avançarmos na discussão sobre o ensino de Ciências no Imperial Instituto dos Surdos-Mudos, optamos por delinear um panorama sobre o ensino de ciências no século XIX, em virtude das especificidades presentes no sistema educacional brasileiro, em vias de desenvolvimento e aprimoramento.

No período do Brasil Colônia até o início do século XIX, a educação brasileira tinha uma tradição de ensino na qual disciplinas como retórica, gramática e línguas estrangeiras apresentavam maior relevância, sendo as disciplinas científicas quase inexistentes nos currículos das escolas de ensino primário e secundário. Nesse período, a história da ciência se confundia com a história da física, da astronomia, da medicina e de outras áreas das ciências, sendo difícil balizar um limite entre as disciplinas de cunho científico, pois a configuração disciplinar, tal como é atualmente dividida (física, biologia, química, astronomia e geociências), foi construída no decorrer do século XIX (VIEIRA; VIDEIRA, 2007).

Com a chegada da família real portuguesa em 1808 ao Brasil, e também com a abertura dos portos brasileiros para os outros países, houve a inserção de disciplinas científicas no currículo das escolas brasileiras de ensino primário e secundário. A abertura dos portos teve um papel importante, pois propiciou as relações e trocas intelectuais do Brasil com os países da Europa (ALMEIDA JÚNIOR, 1979). Essas trocas intelectuais aconteciam principalmente entre o Brasil e a França, país que teve grande influência nas tendências e reformas na educação brasileira.

Quando se discute o ensino de Ciências no século XIX é importante delimitar inicialmente o que englobava tal ensino, pois, na escola, os fenômenos naturais eram estudados e abordados em disciplinas com diferentes nomes. Os conhecimentos científicos eram trabalhados em disciplinas intituladas ciências naturais, astronomia, zoologia, botânica, mineralogia, chimica, physica, zoologia, geologia, biologia, mecânica, astronomia e higiene (LORENZ; VECHIA, 2011).

Nesse sentido, quando utilizarmos nesta pesquisa genericamente o termo sciencias naturaes, estamos nos referindo ao ensino dessas diversas áreas do conhecimento, que visam investigar tudo o que está relacionado aos fenômenos da natureza, tais como o universo, os fenômenos que envolvem os seres vivos, a matéria, a energia, as reações químicas, entre outros; sem nos atermos aqui em uma taxionomia estabelecida.

Em relação ao ensino de Ciências, de acordo com Souza (2000), havia críticas à sua inclusão no ensino primário e elas apontavam que os conhecimentos estavam fora do alcance das crianças e era necessário, para ministrar tal ensino, um profissional com conhecimentos enciclopédicos e equipamentos escolares custosos como laboratórios, gabinetes e oficinas. Por esse motivo, muitas vezes o ensino de ciências ficava restrito aos últimos anos do ensino secundário e as disciplinas de caráter humanista dominavam o currículo do ensino primário.

Apesar das críticas, no ensino primário era recomendado o desenvolvimento de noções elementares baseadas no conhecimento científico e no cotidiano da criança. Dessa forma, era de menor importância a memorização de conceitos e fatos e se recomendava o desenvolvimento de habilidades intelectuais elementares (SOUZA, 2000).

Após a promulgação da Constituição de 1824, em relação à educação secundária, nível em que o ensino de Ciências era concebido de maneira mais clara, poucas iniciativas foram 
tomadas. Em $1838^{5}$ foi criado o Imperial Collegio de Pedro II com o objetivo de formar uma elite dirigente. Esta era uma reconhecida instituição de ensino, com um curso de seis a oito anos de ensino regular, cujas teorias, práticas pedagógicas e matriz curricular foram inspiradas pela França (LORENZ; VECHIA, 2011). O Imperial Collegio de Pedro II era considerado uma escola-modelo no Brasil, assim, a intenção era que as ações pedagógicas nele praticadas fossem reproduzidas por outras Instituições de Ensino do país. Foi nesse período, a partir de 1837, que a disciplina de sciencias naturaes começou a ser ensinada de maneira mais clara e intencional na escola de nível secundário, no Imperial Collegio de Pedro II (LORENZ, 2007).

Contudo, a literatura apresenta que, mesmo havendo um laboratório para o ensino de Ciências no Colégio Pedro II, até meados do século XIX, os professores não utilizavam tal metodologia frequentemente, apenas algumas vezes e em casos isolados (BENETI, 2014). Assim, a realidade era caracterizada por alunos desmotivados com a ciência, desinteressados em virtude de uma educação predominantemente literária, livresca e retórica que tinha se instaurado desde a época do Brasil Colônia e que perduraria até o fim do Brasil Império (ALMEIDA JÚNIOR, 1979). Em alguns aspectos, esse tipo de educação se estende até a atualidade, em algumas realidades escolares. A respeito das aulas de ciências:

[...] as mínimas aulas de Física, Química e Matemática amontoavam-se nos últimos anos atropeladas com as línguas clássicas e modernas e, a exigência maior de matérias de humanidades nos exames preparatórios para o ingresso nas escolas superiores, desobrigando ou reduzindo as aulas de Física a meras noções gerais, prejudicaram profundamente os progressos dos estudos científicos (ALMEIDA JÚNIOR, 1979, p. 54).

Na segunda metade do século XIX, a relevância da aplicação da ciência no cotidiano e na economia a coloca em destaque e, no Brasil, com base na experiência inglesa e francesa, os gestores da educação argumentavam sobre a importância da inclusão do ensino de Ciências (ciências físicas e naturais) no currículo da educação primária brasileira (SOUZA, 2000). A autora afirma que a importância desse ensino foi elevada em função de suas contribuições para o desenvolvimento do intelecto dos alunos, fomentando a curiosidade, observação, investigação e a sua colaboração no progresso da indústria e no desenvolvimento da economia.

No ano de 1854, o Decreto n. ${ }^{0} 1.331$-a, de 17 de fevereiro de 1854, aprovou o Regulamento para a Reforma do Ensino Primário e Secundário do Município da Corte. Nesse decreto, o ensino de sciencias estava previsto:

Art. 47. O ensino primario nas escolas publicas comprehende: A instrucção moral e religiosa, A leitura e escripta, As noções essenciaes da grammatica, Os principios elementares da arithmetica, $\mathrm{O}$ systema de pesos e medidas do municipio. Póde comprehender tambem: O desenvolvimento da arithmetica em suas applicações praticas, A leitura explicada dos Evangelhos

${ }^{5}$ Ano de fundação, mas já estava garantido por lei desde 1837. 
e noticia da historia sagrada, Os elementos de historia e geographia, principalmente do Brasil, Os principios das sciencias physicas e da historia natural applicaveis aos usos da vida, A geometria elementar, agrimensura, desenho linear, noções de musica e exercicios de canto, gymnastica, e hum estudo mais desenvolvido do systema de pesos e medidas, não só do municipio da Côrte, como das provincias do Imperio, e das Nações com que o Brasil tem mais relações commerciaes (BRASIL, 1854, p. 45, grifo nosso).

Essa dimensão curricular norteou o ensino das escolas brasileiras e o artigo 49 desse mesmo Decreto explicitava o que deveria ser ensinado nas escolas de instrução elementar (primeiro grau) e nas escolas de instrução primária superior (segundo grau). No documento em questão, vemos como prescrição o ensino dos princípios das sciencias physicas e historia natural. Lorenz (2010) afirma que a história natural abrangia inicialmente o estudo dos animais, mas, com o passar do tempo, passou a incluir o estudo das plantas e dos minerais, conceito que predominou ao longo do século em questão.

Em relação aos aspectos metodológicos, Lorenz e Vechia (2011) afirmam que o ensino de Ciências no século XIX era baseado nos livros-textos usados nos liceus franceses e redigidos por docentes e cientistas. Os conteúdos eram apresentados em tais livros de maneira enciclopédica e os conhecimentos científicos discutidos eram atualizados. Há indícios de que o professor, em função da dificuldade de achar um texto em português ou pela sua ausência, traduzia o texto aos alunos durante as aulas, e eles lentamente copiavam o que o docente os ditava (LORENZ, 2010). Sobre o material utilizado, Lorenz (2003, p. 7, grifos do autor) afirma que:

Nos programas de 1856 a 1876, a maioria dos livros de ciências naturais foram escritos por autores franceses. Foram citadas as obras de Antoine Paulin Salacroux, François Sulpice Beudant, e Roch Téogéne Guerin. Também apareceram livros de autores brasileiros como o Liçoes elementares de physica de Saturnino Soares de Meirelles e o Quadros synopticos do reino animal... de Joaquim da Silva Maia, professor de Zoologia no Museu Nacional e do Colégio Pedro II, que apresentou o sistema de classficação [sic] do cientista francês, Georges Cuvier.

À época, compêndios de Ciências serviam de referência para a seleção dos tópicos que seriam trabalhados nos programas escolares, mas Lorenz (2010) comenta que as lições listadas em tais programas apresentavam tópicos gerais, não detalhando informações referentes a conceitos apresentados e ensinados em sala de aula.

O Decreto n. 7.247 , de 19 de abril de 1879, que "Reforma o Ensino Primario e Secundario no Municipio da Côrte e o Superior em todo o Imperio", trouxe uma diferença em relação às disciplinas expostas anteriormente para o ensino primário: a inserção da disciplina de Noções de cousas. Para o ensino secundário, tal decreto também propôs algumas alterações:

O ensino nas escolas do $2^{\circ}$ gráo constará da continuação e desenvolvimento das disciplinas ensinadas nas do $1^{\circ}$ gráo e mais das seguintes: Principios elementares de algebra e geometria. Noções de physica, 
chimica e historia natural, com explicação de suas principaes applicações á industria e aos usos da vida. Noções geraes dos deveres do homem e do cidadão, com explicação succinta da organização politica do Imperio. Noções de lavoura e horticultura. Noções de economia social (para os meninos). Noções de economia domestica (para as meninas). Pratica manual de officios (para os meninos). Trabalhos de agulha (para as meninas). (BRASIL, 1879, p. 196, grifo nosso).

Valdemarin (2014) refere que o método intuitivo ou lições de coisas passa a ser utilizado na segunda metade do século XIX em escolas europeias, norte-americanas e brasileiras. De acordo com Auras (2003, p. 313), “[...] o ensino, até então centrado nos textos e livros, cede lugar, no manual de Norman Calkins, ao estudo científico das coisas, centrado na observação e na experiência da criança." A autora ainda aponta que a obra Primeiras lições de coisas - manual de ensino elementar para uso dos paes e professores, de Norman Calkins, que foi publicada em 1861, trazia a seguinte proposta:

Difere o meu livro de outros elaborados por vários professores, numa função importante, a saber: exemplifica ao preceptor o modo de haver-se, em cada passo sucessivo, no desenvolver o espírito das crianças. Depois de dizer o que se há de praticar, passa a mostrar por exemplos demonstrativos o como fazêlo. (CALKINS, 1950, p. 20 apud AURAS, 2003, p. 311).

O método intuitivo tinha alguns pressupostos:

[...] o conhecimento tem início na operação dos sentidos sobre o mundo exterior, a partir do qual são produzidas sensações geradoras de percepções sobre as coisas que, por sua vez, produzem concepções que são retidas pela memória, as quais, acrescidas da imaginação e do raciocínio, possibilitariam o desenvolvimento do juízo e do discernimento. A atenção fixada no que se percebeu, leva à observação, à comparação e à classificação das experiências e dos fatos, produzindo o conhecimento. (AURAS, 2003, p. 312).

A ênfase, à época, era partir do conhecimento das coisas familiares aos alunos, para que, por meio delas, pudessem obter novas ideias, novos conhecimentos:

Assim, é de objetos conhecidos pelas crianças, como bolas, cadeiras, mesas, laranjas, anéis etc., que o professor deve partir, progredindo para a sua forma geométrica, suas propriedades, comparação de formas semelhantes e diferentes, até atividades mais complexas, relacionadas às abstrações. Por isso, as lições propostas partem sempre do simples para o complexo, do concreto para o abstrato, do particular para o geral, da síntese para a análise, do conhecido para o desconhecido, das coisas para as palavras, numa nítida valorização do saber vinculado a resultados práticos e concretos, segundo os pressupostos da pedagogia científica. (AURAS, 2003, p. 313). 
O método intuitivo passa a ser a base para o desenvolvimento do conteúdo das diferentes disciplinas escolares no município da Corte e, por meio da promulgação do Decreto n. ${ }^{\circ} 7247$, de 1879 , a criação de museus escolares também estava prevista (artigo $7 .^{\circ}$ ) e pode ter colaborado para o desenvolvimento de tal método. (BRASIL, 1879).

Almeida Júnior (1979) destaca, no contexto das escolas em geral, que o uso de experimentos também começou a fazer parte do trabalho. A tendência da utilização de experimentos no ensino de Ciências veio por influência alemã, quando houve a reformulação da educação secundária no país, deixando-a mais científica do que literária, e voltada para a formação de cidadãos para as diferentes carreiras profissionais. Contudo, os experimentos eram em sua maioria demonstrativos, e serviam como uma ilustração da teoria apresentada; eles eram manipulados pelo docente sem a participação direta do estudante.

É importante explicitar que a incursão realizada anteriormente visa apresentar, de modo geral, algumas perspectivas e tendências do ensino de Ciências no século XIX. As afirmações são baseadas em relatos da época, documentos oficiais e materiais didáticos utilizados no ensino de Ciências. Outros estudos, tais como os de Almeida Júnior (1979), Beneti (2014), Lorenz (2010) e Takeuchi (2017) trarão com mais detalhes sobre o ensino de Ciências naquele período e evidenciam como as reformas curriculares que aconteceram no Brasil no século XIX $\mathrm{e}$ as tendências internacionais influenciaram o ensino de Ciências no período. De qualquer forma, é importante destacar que em tal contexto também se instaurou o ensino de Ciências para alunos surdos, só que em uma instituição fundada e organizada com o fito de levar a cabo um projeto educacional especializado, acompanhando o pensamento pedagógico, a estrutura e o funcionamento do ensino da época.

\section{O ensino de sciencias para alunos surdos}

O Imperial Instituto dos Surdos-Mudos, desde sua fundação, tinha um programa escolar composto por disciplinas e outras atividades que eram desenvolvidas de forma paralela, visando ao trabalho de reabilitação do aluno surdo e sua "inserção" na sociedade da época, acompanhando as tendências nacionais e objetivando formar cidadãos "úteis" e "[...] com hábito de viver por conta própria” (LEITE, 1868, p. A-D7-3). Em se tratando da primeira instituição especializada para a educação de alunos surdos fundada no país, abarcava uma grande responsabilidade e fazia parte dos projetos imperiais de educação dos alijados da sociedade da época, assim como os alunos cegos e outros grupos considerados vulneráveis, em função de suas variadas condições.

Os alunos que adentravam no Imperial Instituto de Surdos-Mudos, a exemplo de outros colégios da época, receberiam uma educação integral, alicerçada em preceitos morais e religiosos, além do trabalho pedagógico, composto por noções de artes e sciencias (BRASIL, 1856). O tipo de ensino oferecido no Imperial Instituto dos Surdos-Mudos, em princípio, era de caráter primário e secundário (BRASIL, 1856). Quando o Instituto foi fundado, meninos e meninas com surdez poderiam solicitar a matrícula por requerimento, mediante a apresentação de alguns documentos, tais como: atestado do pároco e das autoridades da residência, atestado de vacina com bom resultado, atestado que comprovasse ser surdo-mudo e a não existência de doença contagiosa (BRASIL, 1867).

De acordo com o recorte temporal estabelecido para este estudo, ou seja, de 1856 a 1889, quatro diretores foram os responsáveis pela instituição: E. Huet (1856 a 1861), frei 
João de Nossa Senhora do Carmo (1861 a 1862), Manoel de Magalhães Couto (1862 a 1868) e Tobias Rabello Leite (1869 a 1889). A gestão mais longa foi a do último diretor, que adentrou a República (BRASIL, 1856, 1861, 1862, 1868, 1869, 1889).

Ao longo do período estudado, observou-se também que, além do trabalho pedagógico realizado, alguns alunos também participavam de oficinas, “[...] habilitando-os para exercerem profissões mecânicas" (BRASIL, 1865, p. 20). Uma das primeiras oficinas a serem oferecidas era a de marcenaria, que funcionava em caráter provisório, em 1865. Tal oficina era oferecida para os meninos. Com o passar dos anos, outras foram sendo implantadas com a mesma finalidade, tais como a de horticultura, sapataria e alfaiataria. Sobre isso, Leite (1868, p. A-D7-6) ponderava:

O ensino profissional não é só um benefício para todos os que são educados em estabelecimentos como este, é também uma conveniência para o Estado, poisque a instrucção litteraria sem uma profissão, e sem o habito do trabalho, seria um dom improfícuo, e muitas vezes funesto ao surdo-mudo, por sugerir-lhes ideias e esperanças incompatíveis com o seu estado.

Diante desse cenário, ao analisar o programa escolar destinado aos alunos surdos, verificar as matrizes curriculares do Imperial Instituto dos Surdos-Mudos, constatou-se que a disciplina de sciencias naturaes não estava incluída, não fazia parte do currículo prescrito ou regulamentado. De acordo com Sacristán e Gómes (1998, p. 139), o currículo prescrito é aquele que surge no "[...] âmbito de decisões políticas e administrativas". O autor apresenta o currículo como um processo e, nessa perspectiva, o currículo prescrito seria uma dimensão, assim como o currículo planejado, avaliado, organizado e o em ação. Podemos verificar o oferecimento de disciplinas e demais atividades no Imperial Instituto de Surdos-Mudos por meio dos quadros 1 e 2:

Quadro 1 - Disciplinas oferecidas no Imperial Instituto de Surdos-Mudos (1856-1889)

\begin{tabular}{|l|}
\hline \multicolumn{1}{|c|}{ Disciplinas (1856-1889) } \\
\hline Escripta e leitura \\
\hline Elementos da língua nacional-grammatica \\
\hline Noções de religião e dos deveres sociaes - cathecismo \\
\hline Geographia \\
\hline História do Brasil \\
\hline Historia sagrada e profana \\
\hline Arithmetica \\
\hline Algebra \\
\hline Desenho \\
\hline Escripturação mercantil \\
\hline Economia domestica \\
\hline Gynmnastica \\
\hline Linguagem escripta \\
\hline Mathematica \\
\hline
\end{tabular}

Fonte: Almanak Administrativo, Mercantil... (1856-1889). 
Quadro 2 - Demais atividades oferecidas no Imperial Instituto de Surdos-Mudos

\begin{tabular}{|l|l|}
\hline \multicolumn{1}{|c|}{ Meninos } & \multicolumn{1}{c|}{ Meninas } \\
\hline Horticultura & Costura e mais trabalhos de agulhas \\
\hline Sapataria & Economia doméstica \\
\hline Alfaiate & \\
\hline Marceneiro & \\
\hline
\end{tabular}

Fonte: Almanak Administrativo, Mercantil... (1856-1889).

Esse fato nos causou estranhamento, visto que esse componente poderia ser ensinado no ensino primário, de acordo com o Decreto n..$^{\circ}$ 1.331-a, de 17 de fevereiro de 1854 (BRASIL, 1854), que aprovou o Regulamento para a Reforma do Ensino Primário e Secundário do Município da Corte, conforme já destacado neste estudo. A promulgação desse decreto é anterior à fundação do Instituto.

Diante do exposto, coube-nos a seguinte indagação: por que os alunos surdos não tinham acesso aos conteúdos relativos às sciencias naturaes? Será que estes eram trabalhados de uma forma diferenciada ou eram inviabilizados?

Com base na análise no Decreto Imperial n. ${ }^{\circ} 1331$-a, podemos inferir que as escolas poderiam estabelecer seu currículo, de acordo com a sua realidade e a importância para os alunos. Talvez, por esse motivo, a disciplina de sciencias naturaes não aparecia de forma explícita no currículo, pois o interesse primordial para com a educação de surdos era a reabilitação, comprovada por meio da ênfase dada ao trabalho para a aquisição de língua e linguagem por meio de métodos peculiares.

Durante o período estudado, tal aspecto sobressaía nos documentos analisados. Como exemplo, temos a seguinte afirmação do diretor Tobias Rabello Leite (LEITE, 1870, p. A-E2-4): “[...] a educação litteraria limitou-se ainda ao ensino da linguagem escripta, pelo methodo intuitivo, o melhor de que tenho noticia, com pequenas modificações nos programmas exigidas pelo gosto ou pela conveniência dos respectivos professores".

$\mathrm{Na}$ análise dos relatórios dos diretores do Imperial Instituto dos Surdos-Mudos, encontramos a primeira menção relativa às sciencias naturaes no ano de 1871 , quando o diretor do Instituto, Tobias Rabello Leite, relatou que os alunos surdos faziam perguntas contínuas sobre os phenomenos naturaes: Por que chove? Para que serve o sol? Por que o gato, o cão ou outro qualquer irracional não fala? Diante de tais questões, o diretor mencionava que era necessário ao professor "muito saber" para responder em "termos convenientes", sem dar "ideias errôneas" aos alunos surdos. E ainda complementava:

Si o professor não tiver methodo para regular a marcha da instrucção, dentro em pouco a confusão das noções enleiará por tal fórma a intelligencia do surdo-mudo, que elle não poderá proseguir; si não tiver criterio, as ideas falsas ou perigosas desviarão primeiro o espírito, e depois o coração do surdo-mudo; si não tiver saber, perderá a confiança do seu discipulo, porque muitas vezes não saberá ensinar o que elle deseja saber. Neste período o surdo-mudo é uma machina de perguntas; é uma corrente de curiosidade; quer saber a causa, e o fim de tudo. (LEITE, 1871, p. A-C2-5). 
Por meio desses excertos, percebemos que os fenômenos físicos eram percebidos pelos estudantes surdos e faziam parte do cotidiano escolar, mesmo não estando explícitos no currículo prescrito. Ao que parece, a curiosidade também fazia parte da vida desses alunos, como a de qualquer criança, e precisava ser satisfeita para que novas dúvidas surgissem e outras descobertas fossem conquistadas. Resta saber como eram encaminhadas essas questões pela escola para surdos, uma vez que o próprio diretor assumia que eles precisavam adquirir a linguagem escrita para que os conhecimentos escolares fossem adquiridos. A linguagem oral parecia insuficiente, de acordo com os registros analisados.

Outro fato que pode ter colaborado com a percepção dos alunos surdos para com os fenômenos naturais diz respeito à criação da atividade de horticultura. $\mathrm{O}$ diretor Tobias Rabello Leite justificava sua criação:

Não se tendo estabelecido oficinas no Instituto, nem tido sido possível leval-o para as proximidades dos arsenais, continuarão os alunmos maiores de 14 annos na applicação que lhes dei da pequena horticultura, porque continuo a crer que a agricultura é a profissão que mais convém ao surdo-mudo brasileiro. Não tem sido estéril esta pequena experiencia porque a percepção dos pequenos lucros, produzidos pelo que cada um colheu do pequeno espaço de terreno que lhes dei para lavrar, despertou nelles amôr pelo trabalho, mostrando-se convencidos de que é o meio mais seguro de ganhar dinheiro. (LEITE, 1869, p. A-F4-2).

Essa atividade, em princípio, serviria como uma "distração" para os alunos surdos. Com o passar do tempo, ela foi sendo mais motivada e se tornou uma oportunidade para a aquisição de uma profissão, tendo em vista a condição dos surdos ao se tornarem egressos e, também, o desenvolvimento agrícola do país, em expansão e com a necessidade crescente de mão de obra. Apesar dessa intenção, o contato com a natureza e seus ciclos perpassava em paralelo, com o progresso da horticultura.

Uma análise mais apurada do corpus documental nos permitiu perceber que o tipo de instrução oferecida aos alunos surdos foi se modificando ao longo dos anos, mais precisamente a partir de 1872, quando o diretor Tobias Rabello Leite declarou que a instrução oferecida na instituição seria a primária, dada a condição acadêmica dos alunos que ali se encontravam. Contudo, no mesmo corpus documental não encontramos qualquer alteração no caráter da instituição vinda da Corte, somente as elucubrações do diretor em questão, muito convincentes em função da argumentação que apresentavam. Assim sendo, fica difícil precisar, com certeza, se houve mudança oficial ou não nesse sentido.

Em 1873, Tobias Rabello Leite, ao se referir à instrução que os alunos recebiam no Imperial Instituto de Surdos-Mudos, dizia que os discentes que completassem os estudos levariam a seguinte bagagem acadêmica:

Além de saber ler, escrever corretamente, e as operações arithmeticas mais necessárias na vida comum, levará noções de geometria e de agrimensura, de geografia e historia pátria, das artes mecanicas, das sciencias naturaes e dos seus deveres e direitos como cidadãos: com essa instrucção 
mais ou menos perfeita conforme as intelligencias e applicações, e com a educação moral que tiver gravado no seu espírito a convicção de que o trabalho nobilita e é a fonte mais pura do contentamento, os surdos-mudos serão cidadãos tão uteis como os falantes (LEITE, 1873, p. A-C2-5).

Por meio do excerto, temos outra evidência que os conteúdos de sciencias naturaes eram trabalhados com os alunos durante a vida escolar deles de alguma forma, embora não estivesse prevista no currículo. Não encontramos mais detalhes sobre a forma que esse ensino era conduzido, tampouco quanto aos conteúdos que serviam de referência. Esse fato também era observado nas escolas de ouvintes, no que tange ao ensino de Ciências (LORENZ, 2010). Não localizamos no corpus documental informações sobre compêndios ou livros didáticos usados para tal ensino no instituto, somente existe menção a materiais destinados ao ensino de língua portuguesa, matemática e educação moral.

Em 1877, o conselheiro Carlos Leôncio de Carvalho discriminou em seu relatório que o material do Imperial Instituto dos Surdos-Mudos tinha sido enriquecido com duas coleções de vários objetos, uma oferecida pelo imperador D. Pedro II e outra pelo ministro do Império para a formação de um museu escolar. No ano seguinte, o museu tornou a receber mais materiais, por oferta do próprio diretor Tobias Rabello Leite. A doação era uma coleção completa de cereais, "[...] além de amostras de diversos produtos da canna de assucar, da mamona, do côco, da lã animal, da piassava, do taquarassú, do osso, do chifre e do algodão" (BRASIL, 1878, p. 24). O relatório em questão não apontava o trabalho que seria desenvolvido com tais coleções, mas eram produtos naturais, propícios para o estudo de Ciências.

No ano de 1878, havia nos relatos do diretor Tobias Rabello Leite uma grande menção ao museu escolar, instituído no Imperial Instituto de Surdos-Mudos. O referido gestor apresentou como se deu a organização do acervo do museu, cujas coleções proporcionavam grande proveito para o ensino dos alunos surdos. Faziam parte do acervo os seguintes itens:

Utensílios domesticos feitos de madeira; produtos vegetaes que formam a alimentação do homem sob as diversas formas porque são consumidos, a saber: mandioca em farinha; polvilho; milho em grão; cangica; fubá; maizena; arroz em casca, descascado em fubá; café em côco, descascado, torrado e moído; canna de assucar em melaço; assucar mascavo; branco, refinado, cristalisado e aguardente. Produtos vegetaes necessários para o bem estar do homem, a saber: algodão desde o caroço, gradativamente até o tecido mais fino como no estado natural e nos artefatos mais conhecidos e usados; o taquarassu no estado natural e nos utensílios uzados pelos campeses de S.Paulo, e Minas; piassava em lio e em suas diversas aplicações. Produtos animaes de que serve o homem para o seo tem e ter, taes como: a lã, desde o seu natural gradativamente até o tecido mais fino; o couro desde o seo estado natural ou cru gradativamente desde a sua aplicação mais delicada; a pellica; o osso no estado natural, e nos artefatos mais communs até o carvão animal; o chifre no seo estado natural, e nos artefatos mais usados (LEITE, 1878, p. A-B1-5). 
Por meio dos itens expressos que compunham o museu escolar, infere-se que conteúdos relativos às sciencias naturaes eram abordados por meio das lições de coisas, inerentes ao método intuitivo. Esse método também passou a ser utilizado com alunos surdos no Imperial Instituto dos Surdos-Mudos e se tornou a base para o desenvolvimento do trabalho pedagógico com tais alunos, nas diferentes disciplinas que faziam parte do currículo, mesmo diante das especificidades que se faziam necessárias para o trabalho com o referido alunado.

Com base nos itens expressos na citação de Leite (1878), podemos deduzir que, possivelmente, conhecimentos de botânica e história natural eram desenvolvidos com os alunos surdos. Ademais, o ensino aos alunos surdos embasado nas lições de coisas acompanhava uma tendência pedagógica geral do período, não diferenciando procedimentos em função do público-alvo. Esse fato é relevante, pois a educação de caráter especializado tende, muitas vezes, a se diferenciar.

Com base na vivência, promovida pela percepção dos objetos, o diretor Tobias Rabello Leite destacava o museu como algo interessante e manifestava a intenção de aumentar o acervo. No ano de 1879, o museu ampliou o seu acervo por meio de mais doações feitas pelo imperador D. Pedro II. De acordo com Brasil (1880), nessa doação, chegaram as seguintes coleções: duas de modelos de meios de transporte (terrestre e marítimo), uma amostra de materiais empregados em construções, uma de instrumentos de que serviam os operários, uma de habitação, desde o grupo primitivo, até o palácio moderno e, também, duas de instrumentos de caça e pesca. Os relatos selecionados denotam que, aos poucos, o museu escolar ganhava mais coleções e também se assemelhava às escolas de alunos ouvintes, pois estava de acordo com o que propunha a reforma Leôncio de Carvalho, de 1879, no artigo 7. .: “[...] serão criadas, nos diferentes distritos do mesmo município, pequenas bibliotecas e museus escolares" (BRASIL, 1878, p. 278).

O diretor Tobias Rabello Leite, em 1879, destacou as vantagens de ter um museu na instituição. Segundo ele, qualquer pessoa que assistisse às lições perceberia as vantagens que o museu proporcionava aos alunos: "[...] ganha-se tempo, poupa-se trabalho, e o que é de subido valor, capta-se facilmente a curiosidade do discípulo, prende-se a sua atenção que é a grande difficuldade para quem ensina" (LEITE, 1879, p. A-E2-5). Além disso, o gestor dizia que o museu não auxiliava apenas em relação à aquisição de vocabulário, mas também, por meio do método intuitivo, era possível trabalhar quase todas as sciencias, com conteúdos que estavam ao alcance dos alunos, muito proveitosos não só para sua educação moral, como também para suas necessidades de vida. Diante de mais esse registro, quando o referido diretor se reporta à palavra sciencia, pode-se deduzir que as sciencias naturaes também eram contempladas nesse processo, ainda mais se levarmos em consideração a natureza de algumas coleções do museu escolar.

No ano de 1888, no último relatório analisado do período estudado, o ministro e secretário dos negócios do Império, Antônio Ferreira Vianna, menciona a escola agrícola, que teve início com a prática da horticultura, tão incentivada pelo diretor Tobias Rabello Leite em seu início de gestão (BRASIL, 1889). Em tal escola, os alunos surdos se familiarizavam com o cultivo do café, da cana, do cacau, do algodão e de cereais, assim como com a criação de abelhas. Mesmo tendo um viés profissionalizante, a criação de tais insetos, assim como o cultivo de plantas e hortaliças, envolve conhecimentos de ciências. À época, já existiam no Brasil apostilas desenvolvidas para o ensino de Zoologia, elaboradas por Joaquim da Silva Maia, professor do Colégio de Pedro II, tais como os Quadros Synopticos do Reino Animal (LORENZ, 2010). 
Entretanto, não temos registros que evidenciem o uso de tais materiais no Imperial Instituto dos Surdos-Mudos, de forma a tornar o ensino menos "prático", mais reflexivo e significativo.

Assim sendo, percebe-se que o ensino de sciencias naturaes acontecia de forma transversal, perpassando pelas atividades desenvolvidas no âmbito do museu escolar e das práticas da escola agrícola, acompanhando também a tendência de educação geral, que previa para o ensino de segundo grau, de acordo com o Decreto n. ${ }^{\circ}$ 7.247, de 19 de abril de 1879, o ensino de noções de lavoura e horticultura. (BRASIL, 1879).

\section{Considerações finais}

Por meio do estudo empreendido entendemos que o Imperial Instituto dos SurdosMudos tinha um grande projeto educacional, em virtude de sua especificidade (a educação de surdos), e, ao mesmo tempo, por abarcar a responsabilidade de acompanhar as leis e os decretos imperiais, imprescindíveis para o seu funcionamento, com determinações que deveriam ser aplicadas a quaisquer alunos brasileiros.

No que tange ao nosso objeto de estudo, vimos, com base na pesquisa realizada, que a disciplina de sciencias naturaes, tal como aparecia no currículo prescrito de vários colégios imperiais, não estava prevista no currículo do Imperial Instituto de Surdos-Mudos, talvez pelo fato de o colégio se assumir inicialmente como de caráter primário e secundário e depois tendenciar para um ensino de natureza mais elementar, dada a condição linguística e cognitiva do alunado presente.

Pelo cenário delineado, podemos entender que havia um currículo prescrito e um currículo real que desenvolvia conteúdos relativos às ciências naturais. $\mathrm{O}$ estudo minucioso das fontes primárias nos mostrou indícios no que se refere ao ensino da disciplina de sciencias naturaes por meio de diversas atividades desenvolvidas em outros espaços, que não o de sala de aula, que se diferenciavam por serem novidade em uma escola especializada para alunos surdos. Tais conteúdos poderiam ter sido ampliados, mas, ao que parece, essa não era a única tônica que mobilizava as práticas na instituição: era necessário "restituir-lhes a palavra", “[...] arrancar do isolamento que embrutece os infelizes privados do instrumento essencial para a manutenção e desenvolvimento de relações sociaes; é emfim converter em cidadãos uteis à sociedade indivíduos que lhe pesão e a damnificão involuntariamente" (LEITE, 1868, p. A-D7-3).

Acompanhando a tendência geral do ensino que recomendava o trabalho com as lições de coisas, pode-se dizer que o Imperial Instituto de Surdos-Mudos assim o fez em relação ao ensino de sciencias naturaes. A criação do museu escolar, recomendação dada pelo Decreto n. ${ }^{\circ} 7247$ de 1879, conhecido como Reforma Leôncio de Carvalho, também foi uma estratégia fundamental para difundir os conteúdos relativos à área e propiciar o desenvolvimento de uma série de habilidades nos alunos surdos, haja vista as palavras do diretor Tobias Rabello Leite trazidas ao longo desta investigação. Mesmo assim, fica difícil mensurar o aproveitamento dos alunos que tinham acesso aos materiais das coleções apresentadas e o que isso representava para eles.

Em que pese as iniciativas explicitadas sobre a difusão do conhecimento científico, ao que parece, ainda pairou uma incerteza por parte dos educadores da época quanto à importância do aprendizado de sciencias naturaes pelos alunos surdos. Tais iniciativas, por mais 
significativas que foram, também não deixaram de declarar que a abordagem de conteúdos da área era, de certa forma, tangencial, pois o foco maior de todo o trabalho pedagógico era a aquisição da língua portuguesa pelos alunos surdos em sua modalidade oral e escrita, conforme apontado ao longo do estudo.

Ademais, sabe-se que o incentivo para que os alunos surdos adquirissem uma profissão era grande, principalmente na gestão de Tobias Rabello Leite, que, por meio de seus relatos, sempre defendeu que a melhor profissão para os surdos brasileiros seria a de agricultores, pois muitos vinham de famílias cujos pais trabalhavam no campo. Segundo o diretor, os surdos, depois de formados, poderiam voltar para casa e dar continuidade ao trabalho aprendido no Instituto, assim, poderiam prover o seu próprio sustento.

Diante desse panorama, presume-se que o ensino destinado aos alunos surdos, por mais que trouxesse os ares da sciencia e das bellas artes, tinha o caráter utilitarista e estava afinado com o mesmo tipo de instrução destinado à infância pobre brasileira, que recebia da escola lições de moralidade e civilidade objetivando a consolidação de uma ordem social nacional já estabelecida (SOUZA, 2014).

Por derradeiro, com base nos indícios apresentados no presente estudo, uma questão se coloca para futuras investigações: em que momento histórico o ensino de Ciências vai surgir no currículo prescrito para alunos surdos?

\section{Referências}

ALMANAK ADMINISTRATIVO, MERCANTIL E INDUSTRIAL DA CORTE E PROVINCIA DO RIO DE JANEIRO. Rio de Janeiro: Eduardo \& Henrique Laemmert, 1844-1889. 1856-1889. Disponível em: http://objdigital.bn.br/acervo_digital/div_ periodicos/almanak/almanak.htm. Acesso em: 23 abr. 2019.

ALMEIDA JÚNIOR, J. B. Evolução do ensino de física no Brasil: dos jesuítas até o império. Revista Brasileira de Ensino de Física, São Paulo, v. 1, n. 2, p. 45-58, 1979. Disponível em: http://www.sbfisica.org.br/rbef/pdf/vol01a17.pdf. Acesso em: 23 abr. 2019.

AURAS, G. M. T. Primeiras lições de coisas: manual de ensino elementar para uso dos paes e professores. Educar em Revista, Curitiba, n. 21, p. 311-314, 2003. DOI: https://doi. org/10.1590/0104-40602137

BENETI, A. C. A história do ensino de física no Brasil no século XIX: as academias militares e o colégio Pedro II. 2014. 154 f. Tese (Doutorado em Educação para a Ciência) Universidade Estadual Paulista, Bauru, 2014.

BRASIL. Decreto no 1.331-A de 17 de fevereiro de 1854. Approva o Regulamento para a reforma do ensino primario e secundario do municipio da côrte. Coleção de Leis do Império do Brasil, [Rio de Janeiro], v. 1, pt. I, p. 45, 1854. Disponível em: http://www2. camara.leg.br/legin/fed/decret/1824-1899/decreto-1331-a-17-fevereiro-1854-590146publicacaooriginal-115292-pe.html. Acesso em: 3 maio 2018. 
BRASIL. Decreto no 4046 de 19 de dezembro de 1867. Approva o regulamento provisório do Instituto dos Surdos-Mudos. Coleção de Leis do Império do Brasil, [Rio de Janeiro], v. 1, pt. II, p. 452, 19 dez. 1867. Disponível em: https://www2.camara.leg.br/legin/fed/ decret/1824-1899/decreto-4046-19-dezembro-1867-554346-publicacaooriginal-72928-pe. html. Acesso em: 3 maio 2018.

BRASIL. Decreto n. 7.247 de 19 de abril de 1879. Reforma o ensino primário e secundário do município da corte e o superior em todo o império. Coleção de Leis do Império do Brasil, [Rio de Janeiro], v. 1, pt. II, p. 196, 1879. Disponível em: https:/ /www2.camara.leg. br/legin/fed/decret/1824-1899/decreto-7247-19-abril-1879-547933-publicacaooriginal62862-pe.html. Acesso em: 3 maio 2018.

BRASIL. Ministério do Império. Relatorio apresentado à assembléa geral legislativa [na] quarta sessão da nona legislatura: pelo ministro e secretario d'estado dos negocios do imperio Luiz Pedreira do Coutto Ferraz. Rio de Janeiro: Typographia Nacional, 1856. Disponível em: http://memoria.org.br/pub/meb000000404/00019/00019001r.pdf. Acesso em: 22 abr. 2019.

BRASIL. Ministério do Império. Relatorio apresentado á assembléa geral legislativa na primeira sessão da decima primeira legislatura: pelo ministro e secretario de estado dos negocios do imperio José Antonio Saraiva. Rio de Janeiro: Typographia Nacional, 1861.

BRASIL. Ministério do Império. Relatório apresentado á assembléa geral legislativa na segunda sessão da decima segunda [primeira] legislatura: pelo ministro e secretario de estado de negocios do imperio José Ildefonso de Souza Ramos. Rio de Janeiro: Typographia Nacional, 1862.

BRASIL. Ministério do Império. Relatorio apresentado á assembléa geral legislativa na terceira sessão da decima segunda legislatura: pelo ministro e secretario de estado dos negocios do imperio José Liberato Barroso. Rio de Janeiro: Typographia Nacional, 1865.

BRASIL. Ministério do Império. Relatorio apresentado á assembléa geral na segunda sessão da decima terceira legislatura: pelo ministro e secretario de estado dos negocios do imperio José Joaquim Fernandes Torres. Rio de Janeiro: Typographia Nacional, 1868.

BRASIL. Ministério do Império. Relatorio apresentado á assembléa geral na primeira sessão da decima quarta legislatura: pelo ministro e secretario de estado dos negocios do imperio Paulino José Soares de Souza. Rio de Janeiro: Typographia Nacional, 1869.

BRASIL. Ministério do Império. Relatorio apresentado á assembléa geral legislativa na primeira sessão da decima setima legislatura: pelo ministro e secretario de estado dos negocios do imperio Carlos Leoncio de Carvalho. Rio de Janeiro: Typographia Nacional, 1878 .

BRASIL.Ministério do Imperio. Relatorio apresentado á assembléa geral legislativa na terceira sessão da decima setima legislatura: pelo ministro e secretario de estado dos negocios do imperio conselheiro Barão Homem de Mello. Rio de Janeiro: Typografia Nacional, 1880. 
BRASIL. Ministério do Império. Relatorio apresentado á assembléa geral legislativa na quarta sessão da vigesima legislatura: pelo ministro e secretario de estado dos negocios do imperio Antonio Ferreira Vianna. Rio de Janeiro: Typographia Nacional, 1889.

GIL, A. C. Com o elaborar projetos de pesquisa. São Paulo: Atlas, 2002.

LAEMMERT, E. (ed.). Almanak administrativo, mercantil e industrial da corte e provincia do Rio de Janeiro para o anno de 1856. Rio de Janeiro: Eduardo e Henrique Laemmert, 1856. Disponível em: http://ddsnext.crl.edu/titles/88/items. Acesso em: 3 jan. 2018.

LAEMMERT, E.; LAEMMERT, H. (ed.). Almanak administrativo, mercantil e industrial do Rio de Janeiro para o anno bissexto de 1844. Rio de Janeiro: Eduardo e Henrique Laemmert, 1843. Disponível em: http://ddsnext.crl.edu/titles/88/items. Acesso em: 3 jan. 2018.

LEITE, T. R. Instituto dos Surdos-Mudos: relatório do diretor. Rio de Janeiro: Typographia Nacional, 1868.

LEITE, T. R. Instituto dos Surdos-Mudos: relatório do diretor. Rio de Janeiro: Typographia Nacional, 1869.

LEITE, T. R. Instituto dos Surdos-Mudos: relatório do diretor. Rio de Janeiro: Typographia Nacional, 1870.

LEITE, T. R. Instituto dos Surdos-Mudos: relatório do diretor. Rio de Janeiro: Typographia Nacional, 1871.

LEITE, T. R. Instituto dos Surdos-Mudos: relatório do diretor. Rio de Janeiro: Typographia Nacional, 1873.

LEITE, T. R. Instituto dos Surdos-Mudos: relatório do diretor. Rio de Janeiro: Typographia Nacional, 1878.

LEITE, T. R. Instituto dos Surdos-Mudos: relatório do diretor. Rio de Janeiro: Typographia Nacional, 1879.

LIMEIRA, A. M.; SOUZA, F. B. Espaços de aprendizagem para surdos, mudos e cegos: instituições educativas do século 19. Revista Brasileira de Estudos Pedagógicos, Brasília, v. 89, n. 222, p. 325-340, maio/ago. 2008. Disponível em: http://rbep.inep.gov.br/index. php/rbep/article/viewFile/705/682. Acesso em: 22 abr. 2019.

LORENZ, K. Ciência, educação e livros didáticos do século XIX: os compêndios das ciências naturais do colégio de Pedro II. Uberlândia: EDUFU, 2010.

LORENZ, K. M. A influência francesa no ensino de ciências e matemática na escola secundária brasileira no século XIX. In: CONGRESSO BRASILEIRO DE HISTÓRIA DA EDUCAÇÃO, 2., 2003, Natal. Anais [...]. Disponível em: http://www.sbhe.org.br/novo/ congressos/cbhe2/pdfs/Tema3/0306.pdf. Acesso em: 16 out. 2010. 
LORENZ, K. M. A zoologia filosófica no Brasil: explorando as modernas correntes do pensamento científico no Colégio de Pedro II em meados do século XIX. Revista História da Educação, Santa Maria, v. 11, n. 21, p. 133-158, 2007. Disponível em: https://seer.ufrgs. br/asphe/article/view/29394. Acesso em: 23 abr. 2019.

LORENZ, K. M.; VECHIA, A. O debate ciências versus humanidades no século XIX: reflexões sobre o ensino de ciências no Collegio de Pedro II. In: GONÇALVES NETO, W.; MIGUEL, M. E. B.; FERREIRA NETO, A. (org.). Práticas escolares e processos educativos: currículo, disciplinas e instituições escolares (séculos XIX e XX). Vitória: EDUFES, 2011. p. 115-152.

SÁ, N. R. L. Educação de surdos: a caminho do bilinguismo. Niterói: EdUFF, 1999.

SACRISTÁN, J. G.; GÓMES, A. I. Compreender e transformar o ensino. Porto Alegre: Artmed, 1998.

SOUZA, R. F. Espaço da educação e da civilização. In: SAVIANI, D. et al. O legado educacional do século XIX. Campinas: Autores Associados, 2014. p. 35-79.

SOUZA, R. F. Inovação educacional no século XIX: a construção do currículo da escola primária no Brasil. Cadernos Cedes, Campinas, v. 20, n. 51, p. 9-28, 2000. DOI: https:// doi.org/10.1590/S0101-32622000000200002

TAKEUCHI, M. R. Livros escolares e ensino de ciências na instrução pública elementar brasileira do século XIX ao XX. 2017. 227 f. Tese (Doutorado em Educação: História, Política, Sociedade) - Pontifícia Universidade Católica de São Paulo, São Paulo, 2017.

VALDEMARIN, V. T. O método intuitivo. In: SAVIANI, D. et al. O legado educacional do século XIX. Campinas: Autores Associados, 2014. p. 83-125.

VIEIRA, C. L.; VIDEIRA, A. A. P. História e historiografia da física no Brasil. Fênix: revista de história e estudos culturais, Uberlândia, v. 4, n. 3, p. 1-27, 2007.

Artigo recebido em 08/05/2018. Aceito em 20/09/2018.

Contato: Universidade de São Paulo, Faculdade de Educação, Avenida da Universidade, 308, Butantã, São Paulo, SP, 05508-040, Brasil. 
